\title{
COARCTATION OF THE AORTA: THE COLLATERAL CIRCULATION
}

BY

\author{
CRIGHTON BRAMWELL AND A. MORGAN JONES
}

From the Cardiographic Department, Manchester Royal Infirmary

Received June 9, 1941

Coarctation of the aorta imposes a mechanical embarrassment on the circulation and so affords an opportunity of studying problems of both clinical and physiological interest. During the past ten years we have had the good fortune to meet with thirteen patients exhibiting this abnormality, and in the present and future papers it is our object to consider some of the problems presented by this condition.

This paper is concerned with one of our patients in whom the lesion was diagnosed in 1938. Two years later she was admitted to hospital suffering from subarachnoid hæmorrhage, from which she died. This accident gave us the opportunity of studying the collateral circulation, in a patient who exhibited no signs of heart failure, by a method to which we have been able to find only one reference (Ernstone and Robins, 1931). We injected the arterial system with barium paste and took a series of radiograms of the cadaver.

\section{CASE Record}

A nulliparous woman, aged 25, consulted one of us (C. B.) in July 1938 regarding her fitness for pregnancy.

Following rheumatism at the age of 5, a heart murmur had been discovered. At 7 years she was troubled by growing pains. She suffered from chilblains and from cold hands and feet. At school she was never able to play games, and at the age of 15 was off school for a year with dyspnœa and palpitation. In childhood she suffered from migraine, which occurred almost every week and was associated with vomiting and severe bilateral frontal headache; this ceased in adult life. Between the ages of 17 and 24 she worked in an office, and during this period was never absent owing to illness. She gave up this work on marriage, nine months before we saw her.

At that time her chief complaints were of pain below the left scapula, which became worse on exertion, and of occasional dyspnœa, palpitation, and flatulent dyspepsia. . Nevertheless she was able to do all her own housework with the help of a woman on one half-day each week. 
On physical examination the first thing that struck one was the violent arterial pulsation in the neck. The pulse rate was 112 and its rhythm regular; the blood pressure was $235 / 100$ in both arms. On auscultation there was a systolic murmur with an unusual distribution; it was heard both at the apex and at the base of the heart, but was loudest on the back of the chest on the right side, just above the spine of the scapula. The femoral pulse was of small volume, and the systolic blood pressure at the ankle was 140 .

A diagnosis of coarctation of the aorta was made, and was confirmed by radiography (Fig. 1-3). This showed the characteristic notching of the ribs and the absence of the aortic knuckle (Fig. 1); and, in the right oblique position, the absence of the typical aortic impression on the barium-filled œsophagus (Fig. 2). In the electrocardiogram the $T$ wave was diphasic in lead II and negative in lead III. A blood count showed hypochromic anæmia with 70 per cent hæmoglobin. The urine contained a trace of albumin; the specific gravity was 1018 and the renal function tests were satisfactory.

Apart from the pain in the back she remained fairly well until the morning of July 30,1940, when suddenly she was seized by a severe pain in the occipital region; this spread down the back to the legs. She vomited four or five times, became semi-conscious, and subsequently spoke only once to complain of very severe headache. On admission to the Manchester Royal Infirmary that afternoon she was comatose, with signs of severe meningeal irritation. Her pulse was 80, full and bounding, and her blood pressure was 220/115. The left arm and leg were more flaccid than the right, and the left plantar response was extensor. The condition was diagnosed as subarachnoid hæmorrhage, and this diagnosis was confirmed by the withdrawal of a heavily blood-stained cerebrospinal fluid under increased pressure. She died a few hours later.

\section{POST-MORTEM EXAMINATION}

(a) Morbid Anatomy. An autopsy was performed by Dr. W. Susman seventeen hours after death. Apart from œdema of the lower lobes of the lungs and slight generalized passive congestion, the abnormalities found were confined to the brain and cardiovascular system.

The brain weighed 1300 grammes. Blood was present in the subarachnoid space over the right cerebral hemisphere and the pons. A pressure cone was evident and the convolutions were flattened. Most of the outer half of the right parietal lobe had been destroyed by hæmorrhage, and the area was occupied by blood clot; the hæmorrhage had burst into the right lateral ventricle and blood was present in the right lateral, third, and fourth ventricles. In the plane of the pituitary stalk, just below the level of the optic thalamus, there was an aneurysm of the right middle cerebral artery, $0.8 \mathrm{~cm}$. in diameter (Fig. 4). This aneurysm had recently ruptured.

The descending thoracic and the abdominal aorta were rather small. The intercostal arteries, the internal mammary arteries, and the arteries of the head, neck, and upper limbs were enlarged and tortuous. 

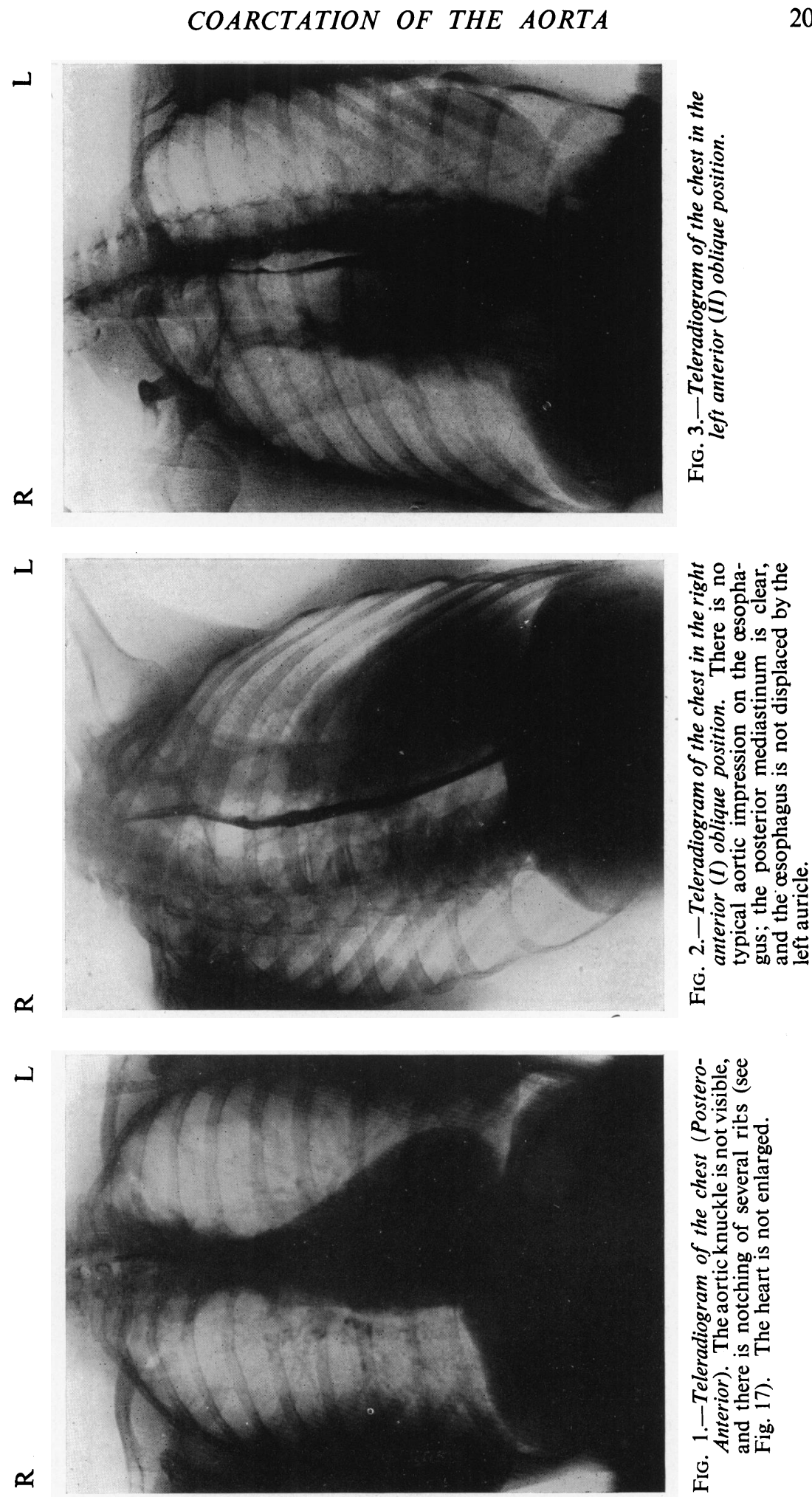


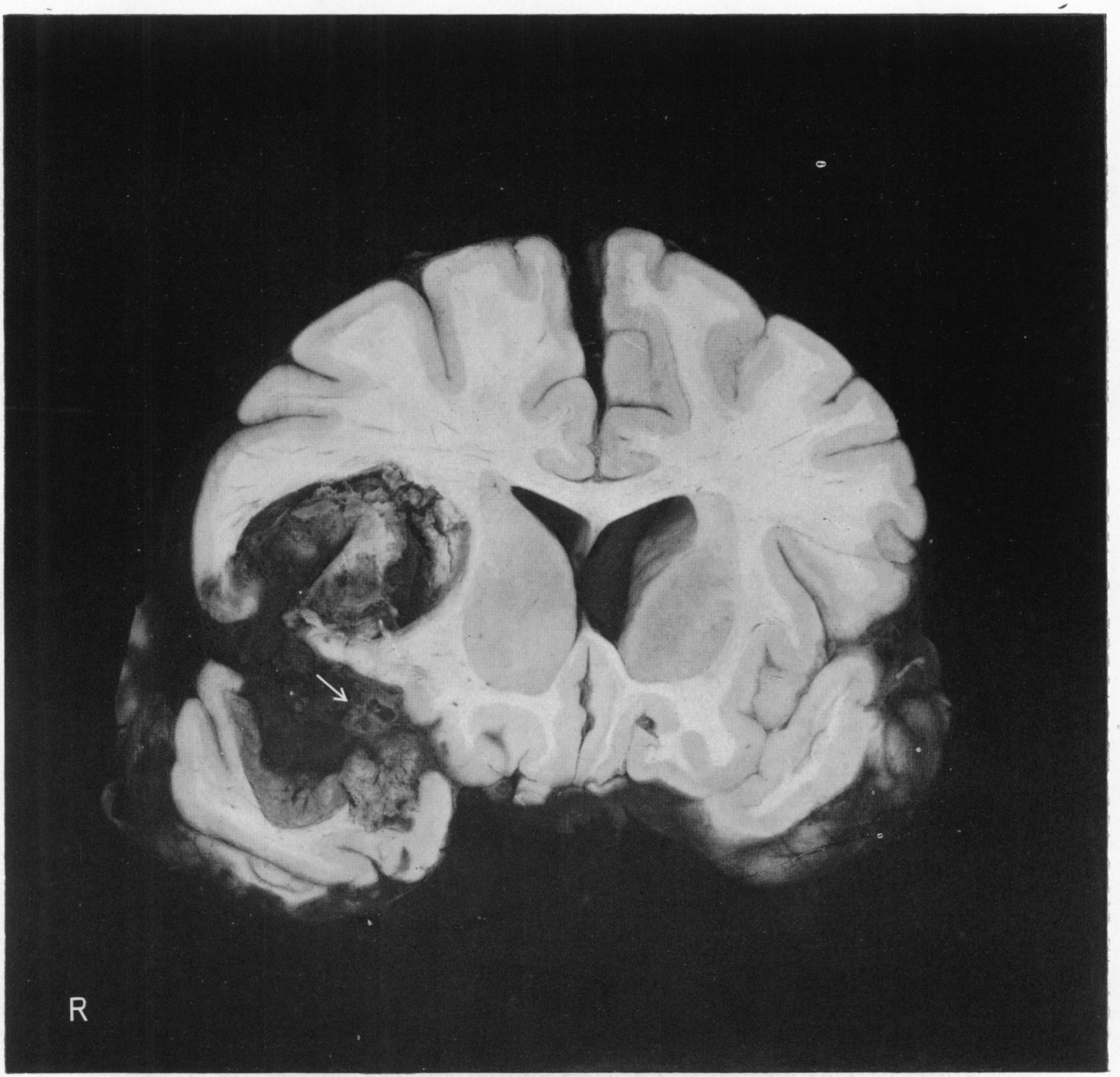

FIG. 4.-Coronal section of the brain. There is a large hæmorrhage in the right parietal lobe. The ruptured congenital aneurysm has been cut across and is indicated by an arrow. This association of congenital cerebral aneurysms with coarctation of the aorta has been noted by various authors (Brown, 1939).

The aorta appeared to be completely occluded at a point on the arch just distal to the left subclavian and near the entrance of the obliterated ductus arteriosus, which was represented by a stout fibrous strand (Fig. 5). The left subclavian artery arose as a direct continuation of the aortic arch and was unusually large. The upper intercostal arteries, entering the descending aorta just distal to the occlusion, were greatly dilated.

The heart weighed 350 grammes. The specimen, unfortunately, was destroyed, as the result of enemy action, before any further examination had been made.

(b) Injection of the Arteries. Prior to autopsy it was decided to attempt to inject the arteries of the intact cadaver with an opaque paste in order to 


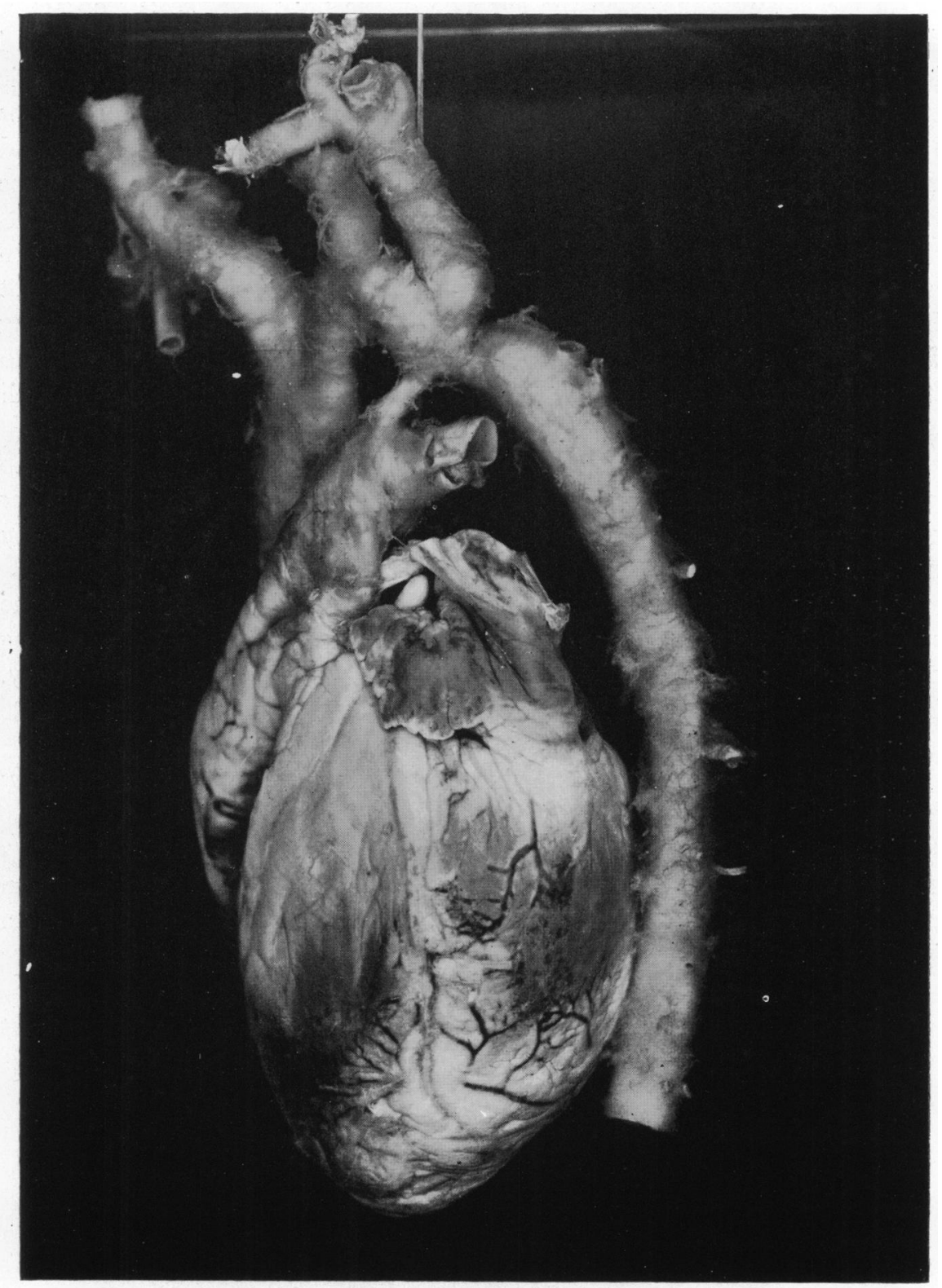

FIG. 5.-The heart. The coarctation is visible just distal to the origin of the left sutclavian, which forms the continuation of the aortic arch. The innominate, the left commcn carotid, the left subclavian, and their branches are greatly enlarged. The upper aortic intercostals are seen cut across and are greatly enlarged. The obliterated ductus arteriosus persists as a fibrous cord. 
study the collateral circulation. Barium enema paste was used, as it was readily available at short notice.

An incision was made on the left side of the neck and the left common carotid artery exposed; a canula was introduced and the barium injected slowly into the arch of the aorta, proximal to the coarctation, under radioscopic control. Films were taken at intervals in the anterior and oblique positions (Fig. 6, 7, 9, 10, and 11) and of the abdominal vessels (Fig. 12). It was found best to keep a moderate pressure on the piston of the syringe during the exposure in order to distend the aorta slightly.

It is important to inject the barium under radioscopic control, in order to ensure that sufficient enters the arteries to outline them satisfactorily without obscuring the larger vessels by filling the arterioles and capillaries. Flooding of the vessels occurs earlier in some areas than in others and it is advisable to take a series of films at different stages of the injection in order to display all the main vessels.

Between 700 and 800 c.c. of barium paste were used in this case. The paste used for barium enemata is suitable for this purpose; a thinner paste is liable to cause flooding before the main vessels are satisfactorily outlined.

The barium was injected above the coarctation, and therefore reached the vessels of the lower part of the body by the collateral channels. The descending aorta, the aortic intercostals, and the abdominal vessels were filled in this way. Since the barium followed the path taken by the blood during life, filling artefacts were avoided.

The results of the injection are shown in Fig. 6-11 which follow, and they are explained in the legends below each.

The first two show an early and late stage of the injection in the ordinary antero-posterior position. The injection canula is seen in the left common carotid. In Fig. 6 the intercostal arteries are only beginning to fill, but in Fig. 7 they are well filled and the tortuosities and notching of the ribs are clearly seen. The coarctation can be seen to the left of the mediastinal shadow and in Fig. 7 the tortuous enlarged subscapular artery can be seen on the right border of the chest. Fig. 8 is a tracing from Fig. 7, naming the arteries that can be seen.

Fig. 9 and 10 show the left (II) oblique positions: in both the coarctation is clearly seen and seems to be complete; in the former it is crossed by two tortuous and enlarged aortic intercostals passing upwards to anastomose with the superior intercostal. In Fig. 11 a clear picture has been taken of the main branches above the coarctation and of some from below (shown in darker shading).

Finally, Fig. 12 shows the abdominal vessels, which must have filled entirely through the collateral circulation, although the well-known anastomosis between the superior and deep epigastric arteries was not developed in this case. The legends below each figure give fuller details. 


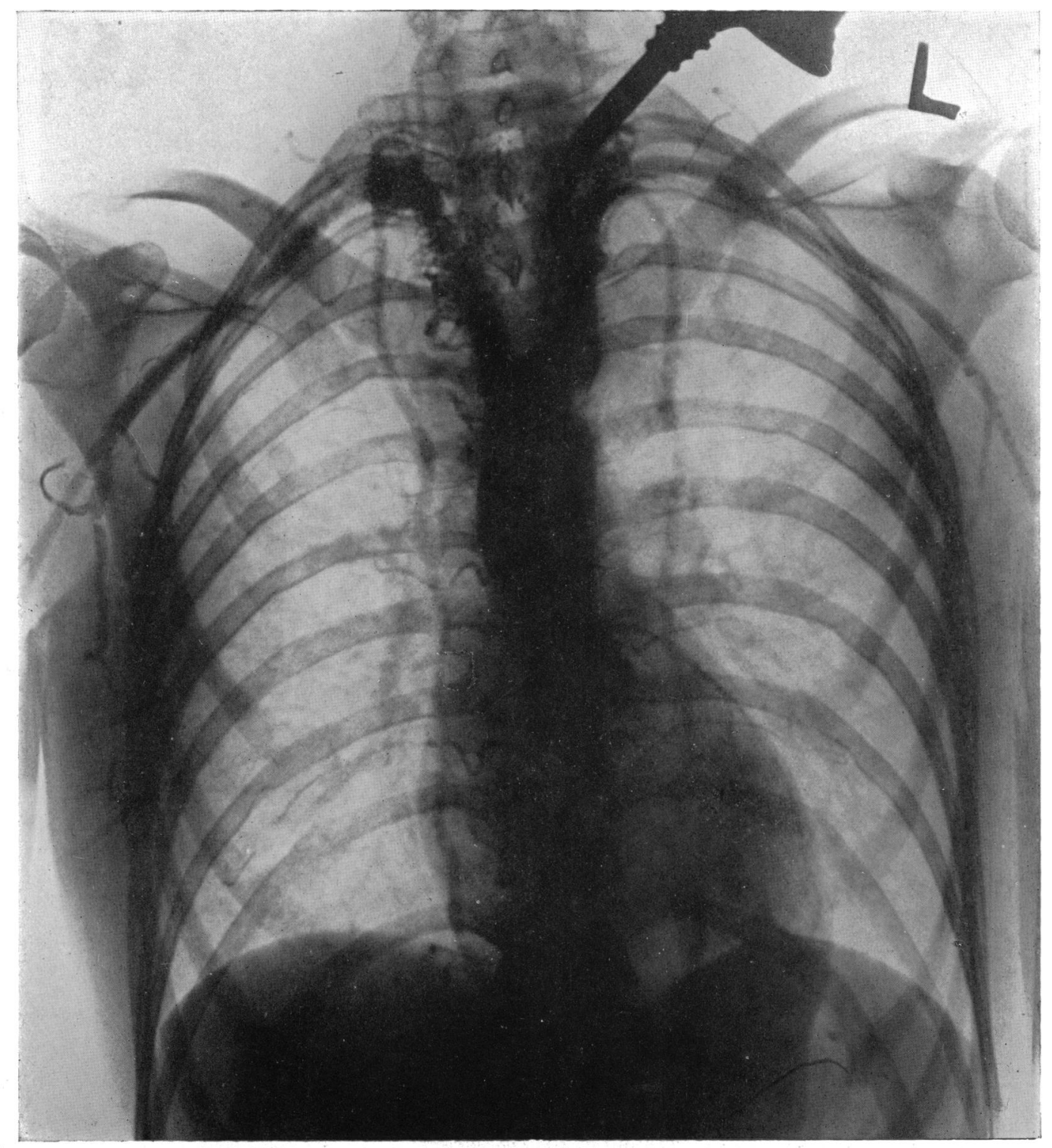

FIG. 6.-Barium injection: Radiogram (P.-A.) at an early stage of injection. The injection canula is seen in the left common carotid artery. The intercostals are commencing to fill by their anastomotic channels. The coarctation is shown to the left of the superior mediastinal shadow; the upper prominence is formed by the tortuous origin of the left subclavian (Fig. 5) and the lower prominence by the blind end of the descending aorta. Between this and the ascending aorta there is a narrow gap. 


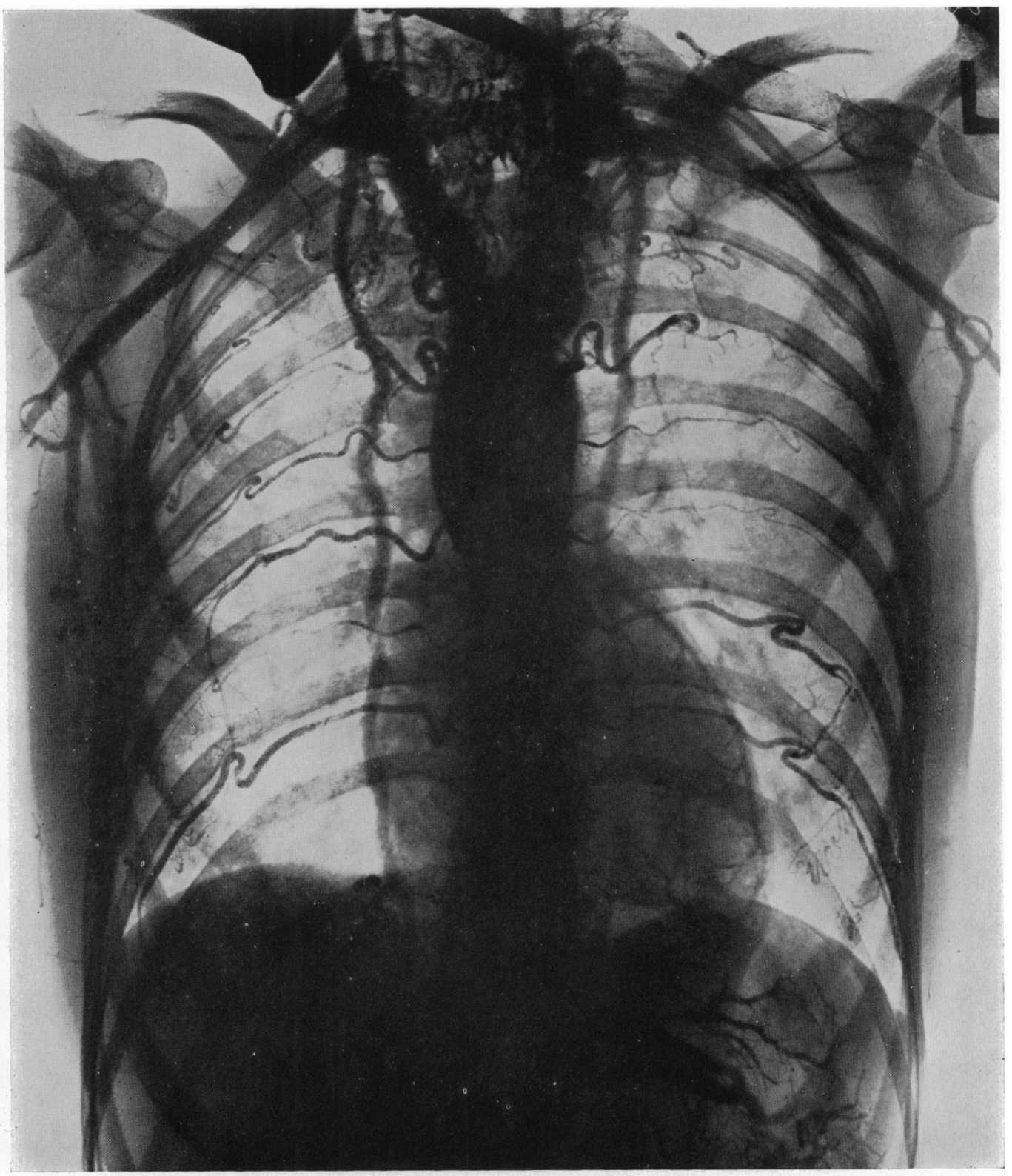

FIG. 7.-Barium injection: Radiogram $(P .-A$.) at the end of injection. The arteries shown on this radiogram are named in Fig. 8. The intercostal arteries have filled and are very tortuous. The notching of the ribs by the arterial loops is obvious. The internal mammary arteries are enlarged and the extensive diaphragmatic anastomosis formed by their musculophrenic branches and the phrenic branches of the aorta is well seen on the left side. The tortuous enlarged subscapular artery is visible on the right border of the chest; its dorsalis scapulæ branch encircles the neck of the scapula. Just medial to its origin is the long thoracic artery. The aortic intercostals supplying the fourth and fifth spaces are much enlarged near their origin from the aorta. This appearance is not a filling artefact, for all the barium was injected above the coarctation. The intercostals, therefore, filled by their collateral channels from the scapular network and the superior intercostal, and the distension near the descending aorta could not have been due to forcing barium into them from the aorta distal to the coarctation. 


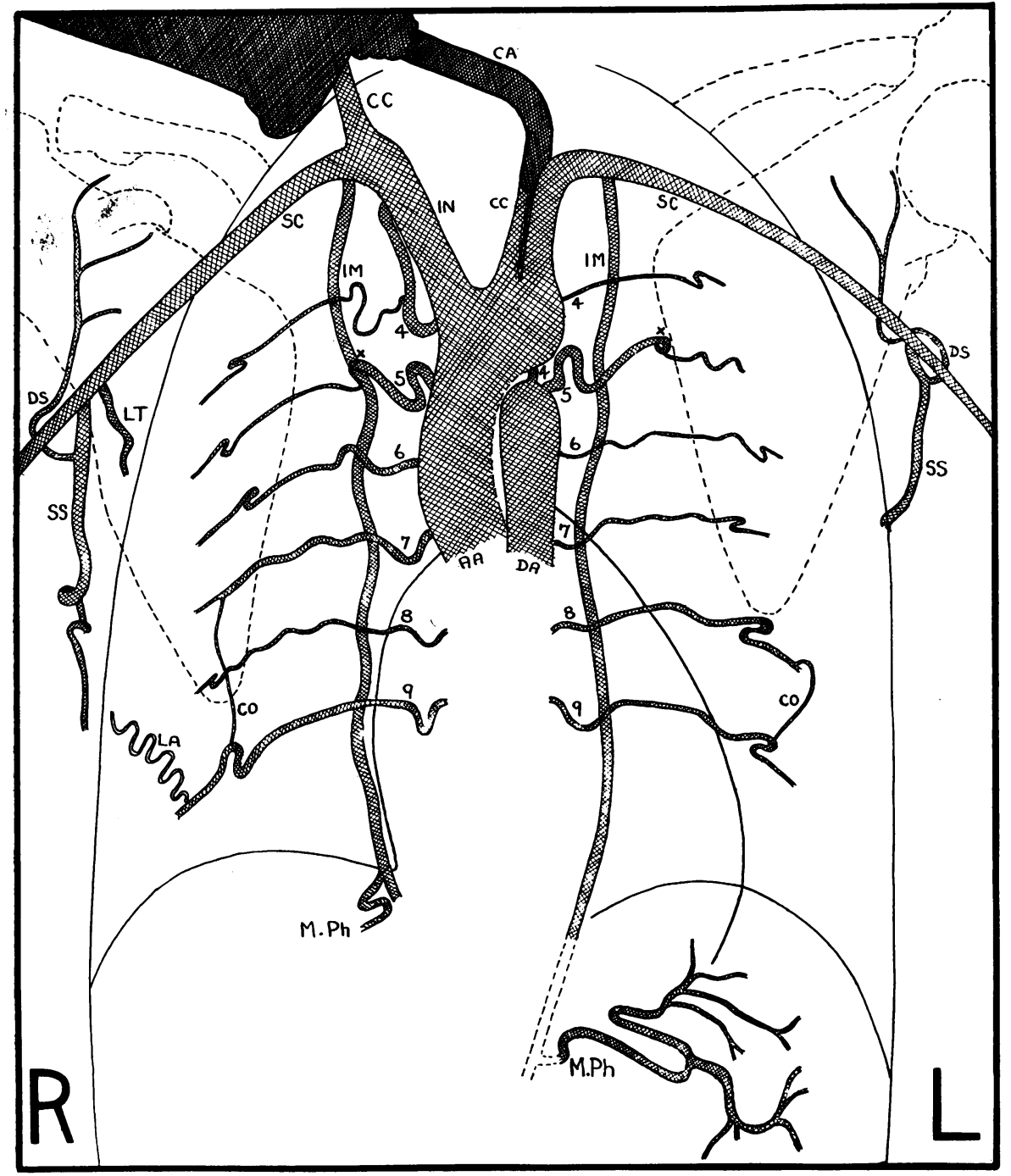

Fig. 8.-Tracing from Fig. 7.

CA-Injection Canula.

ARTERIES.

AA-Ascending aorta.

IN-Innominate.

SC-Subclavian.

LT-Long thoracic.

DS-Dorsalis scapulæ.

LA-Anastomosis of subscapular with aortic intercosta!s.

$4,5,6$, etc.-Aortic intercostals.

DA-Descending aorta.
CC-Common carotid.

IM-Internal mammary.

SS-Subscapular.

M.Ph.-Musculo-phrenic forming diaphraymatic anastomoses.

$\mathrm{CO}-$ Communicating branches between intercostals.

$\mathrm{XX}$-The points at which the second aortic intercostals (supplying the fifth spaces) notch the ribs. 


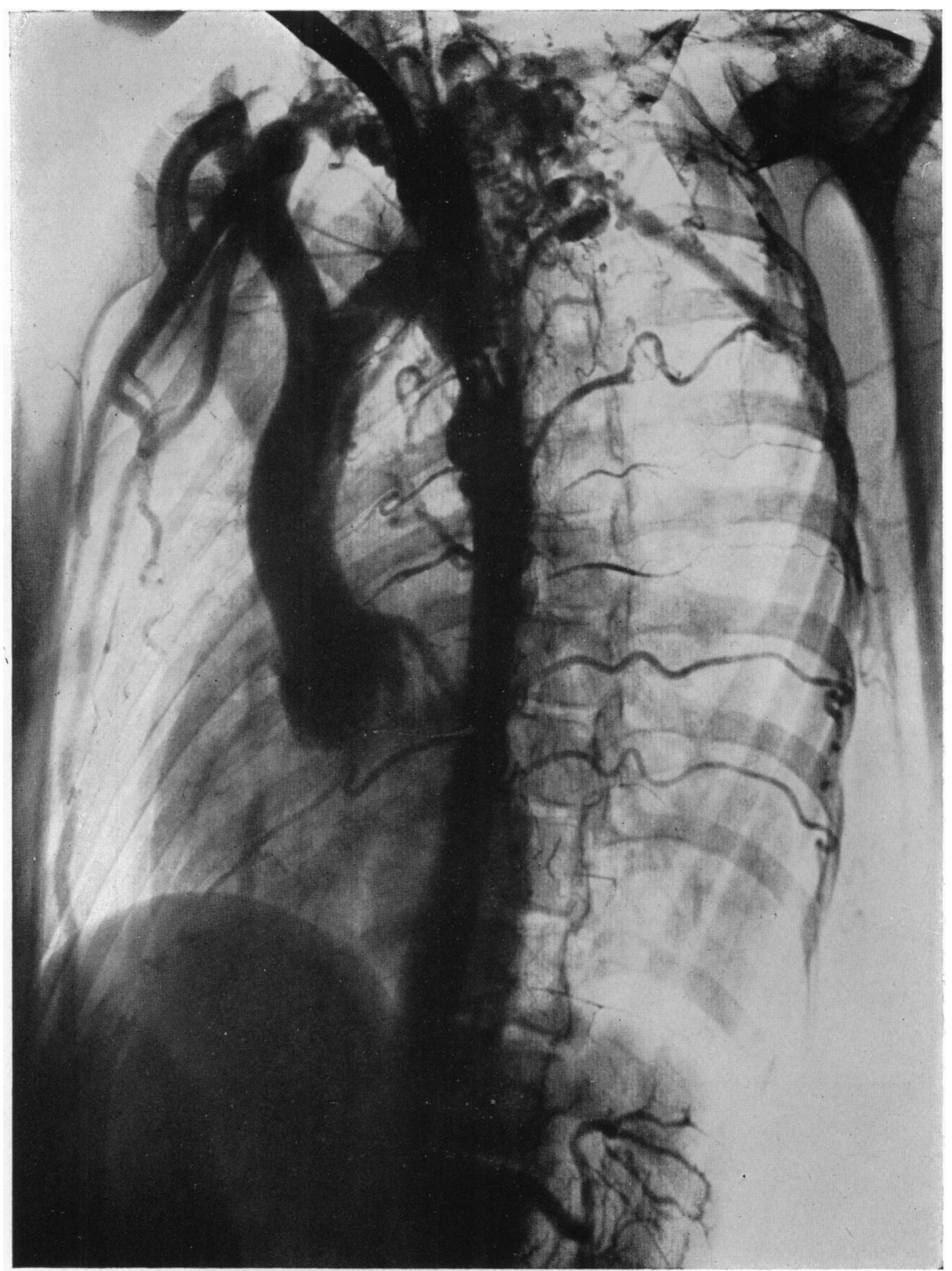

FIG. 9.-Barium injection: Radiogram in the left anterior (II) oblique position, at the end of injection. The coarctation is clearly seen and is crossed by two tortuous and enlarged aortic intercostals passing almost vertically upwards to their anastomosis with the superior intercostal. The extensive diaphragmatic anastomosis is seen. 


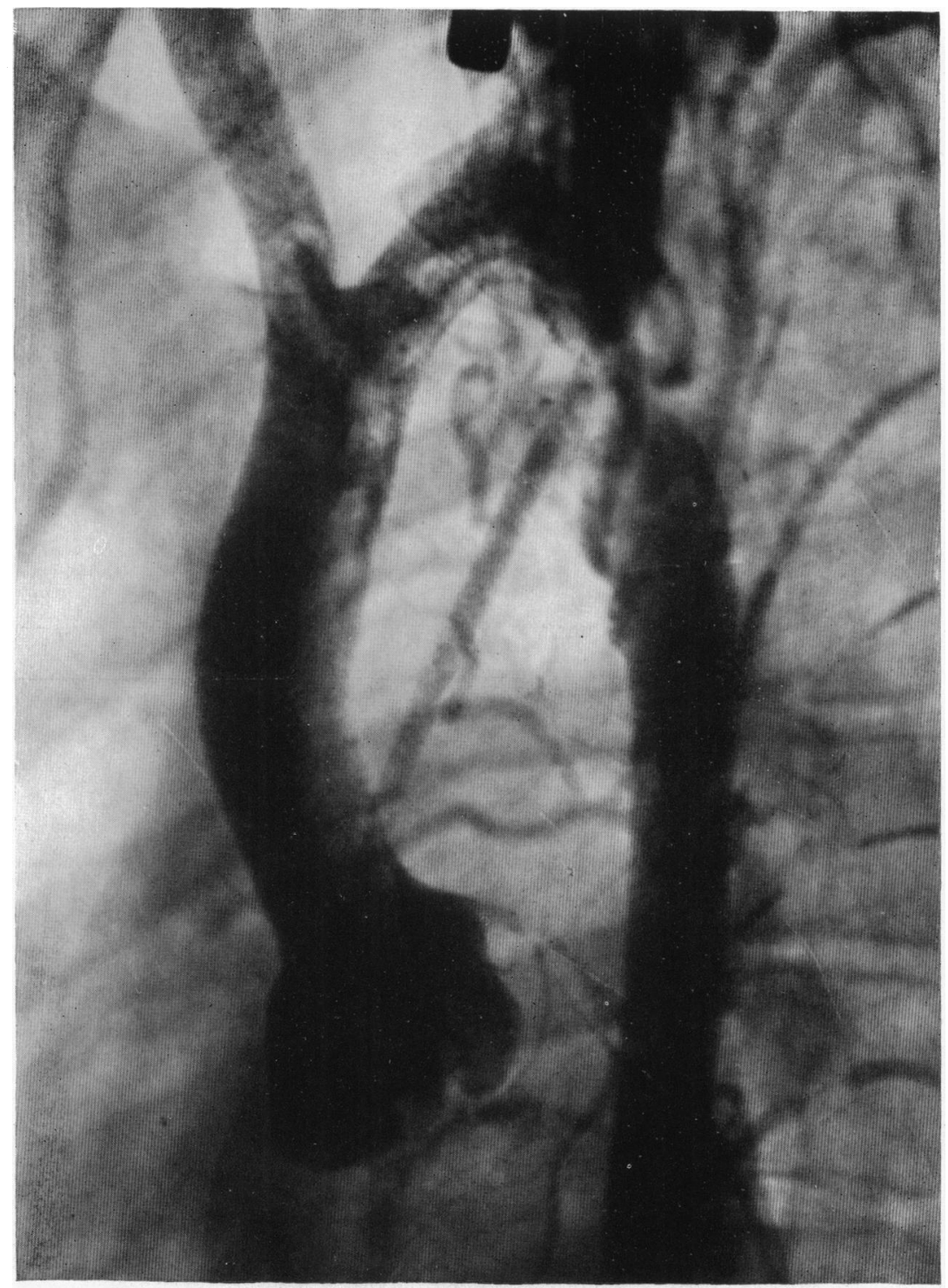

FIG. 10.-Barium injection : Radiogram of the aorta in the left anterior (II) obliaue position. The coarctation is shown and appears to be complete. The aortic valve and the sinuses of Valsalva are seen. The valve is obviously competent. 

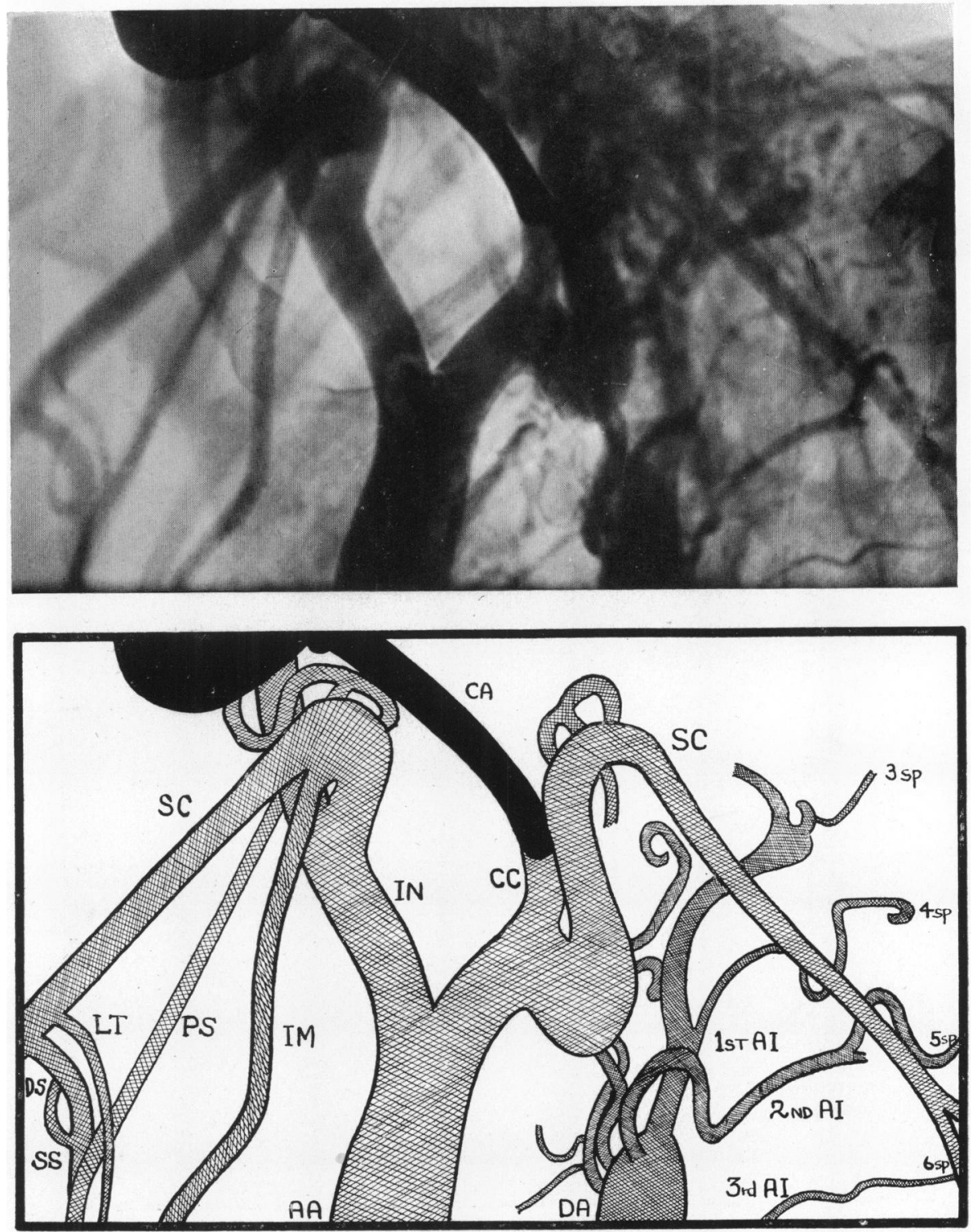

FIG. 11.-Radiogram in a left oblique position, showing the coarctation.

Key.-The arteries arising below the coarctation are represented in a darker shade.

CA-Injection Canula.

LT-Long thoracic.

DS-Dorsalis scapulæ.

SS-Subscapular.

IN-Innominate.

CC-Common carotid.

IM-Internal ma mmary. SC-Subclavian. AA-Ascending aorta. DA-Descending aorta. 1st AI, 2nd AI, etc.- first and second left aortic intercostals, etc.

$3 \mathrm{sp}, 4 \mathrm{sp}$, etc.- branches of left aortic intercostals to third and fourth spaces, etc.

The left subclavian forms a continuation of the aortic arch. The first left aortic intercostal (1st AI) runs almost vertically upwards, and gives off branches to the fourth and third intercostal spaces (4sp and 3sp); its main trunk anastomoses with the superior intercostal. The second and third left aortic intercostals (2nd AI, 3rd AI) are visible. The origins of the right aortic intercostals are hidden by the descending aorta (DA). 


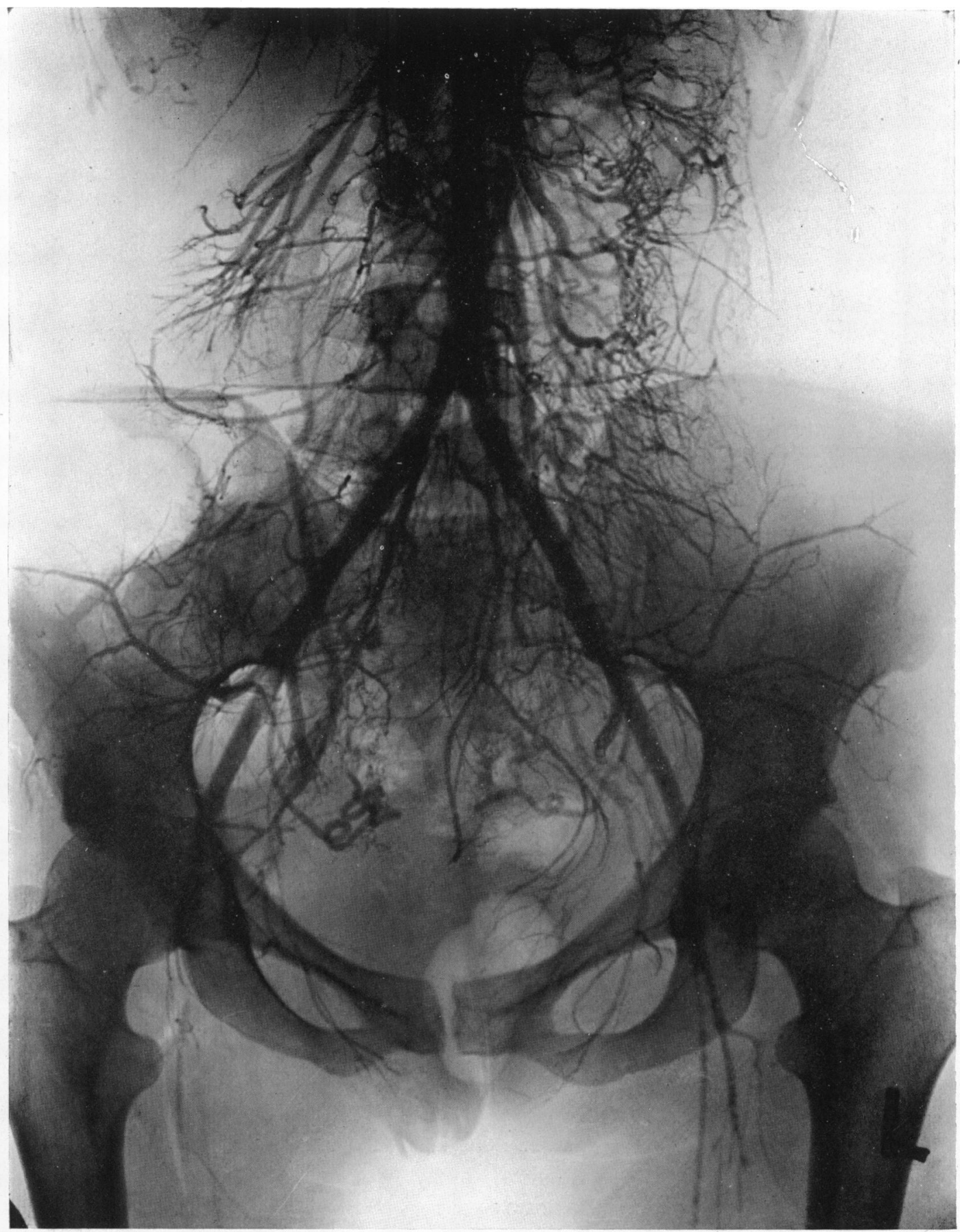

FIG. 12.-Barium injection: Radiogram of the abdominal vessels. The complete injection of the abdominal vessels is shown. As the barium was all injected above the coarctation these must have filled by the collateral channels. The well-known anastomosis between the superior and deep epigastric arteries was absent in this case. 


\section{Discussion}

Clinically, the collateral circulation is revealed by palpable dilated arteries on the back or front of the chest, and by the late systolic murmur sometimes audible over these vessels; radiographically, its important manifestation is notching of the ribs by the enlarged and tortuous intercostal arteries. These features merit further consideration.

\section{The Anastomotic Pattern}

The blood has a choice of routes whereby to reach the aorta beyond the coarctation, and it would be interesting to know whether the circulatory efficiency in different cases is related to the anastomotic pattern.

In Table I we have enumerated, and in Fig. 13 we have endeavoured to depict diagrammatically, the various collateral channels which may be of importance.

\section{TABLE I}

\section{Collateral Channels in Coarctation of the Aorta}

\section{The Scapular and Cervical anastomoses:}

The following arteries form a network around the scapula and in the cervical region:

(a) Suprascapular and transversalis colli (from thyroid axis).

(b) Posterior scapular and superficial cervical (from transversalis colli).

(c) Long thoracic and subscapular with its dorsalis scapulæ branch (from axillary artery).

From this network descending branches anastomose with the lateral and dorsal branches of the aortic intercostals.

2. The Internal Mammary Anastomoses:

(a) Superior epigastric $\rightarrow$ deep epigastric branch of external iliac.

(b) Musculo-phrenic $\rightarrow$ phrenic branches of thoracic and abdominal aorta.

(c) Mediastinal branches $\rightarrow$ mediastinal branches of aorta.

(d) Anterior intercostals $\rightarrow$ terminal branches of aortic intercostals.

3. The Intercostal Anastomoses:

(a) The terminal branches $\rightarrow$ the intercostal branches of the internal mammary.

(b) The lateral branches $\rightarrow$ the subscapular and long thoracic.

(c) The dorsal branches $\rightarrow$ the posterior scapular.

(d) The first and second intercostals (arising from the subclavian by the superior intercostal) $\rightarrow$ the upper aortic intercostals.

(e) Each intercostal $\rightarrow$ those above and below.

4. The Spinal Anastomoses:

The vertebral artery, arising from the first part of the subclavian, reinforces the spinal arteries in which the blood flows downwards to reach the spinal branches of the aortic intercostals. These pass through each intervertebral foramen. There are also branches from the inferior thyroid which pass through the intervertebral foramina in the neck to join the spinal arteries.

In our case the main anastomoses were :

(a) By the scapular and cervical branches of the subclavian and axillary arteries to the lateral and dorsal branches of the aortic intercostals, forming a network around the scapula and in the neck.

(b) By the musculo-phrenic branch of the internal mammary to the 


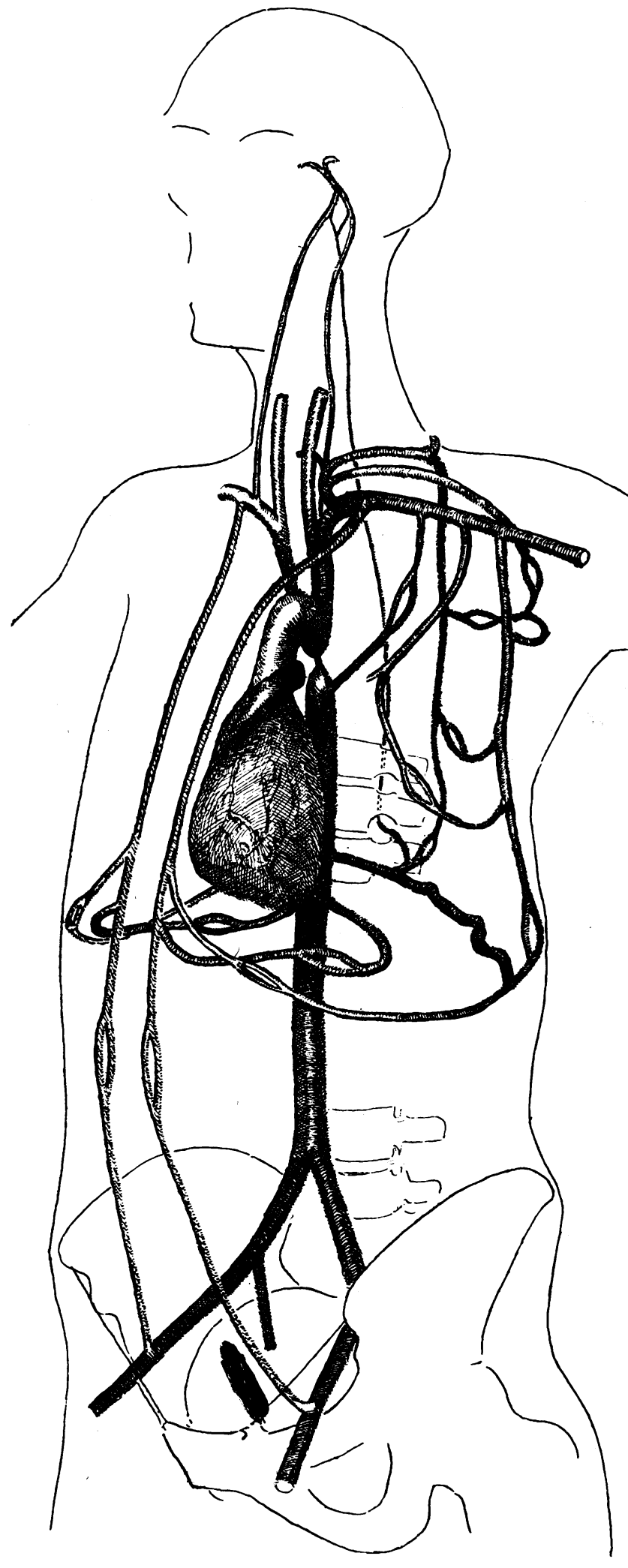

V-Vertebral arteries.

SA-Spinal arteries.

TC-Transversalis colli.

TS-Suprascapular.

SC-Subclavian.

SI-Superior intercostal.

AI-Aortic intercostal (only one represented).

LT-Long thoracic.

PS-Posterior scapular.

SS-Subscapular.

DS-Dorsalis scapulæ.

$\mathrm{Ph}-$ Phrenic branches of aorta.

MP-Musculo-phrenic from internal mammary.

IM-Internal mammary.

SE-Superior epigastric.

DE-Deep epigastric.

SD-Spinal branch of aortic intercostal.

FIG. 13.-The collateral circulation in coarctation of the aorta.

This diagram illustrates the available collateral channels. All of these are not necessarily enlarged in any particular case. 


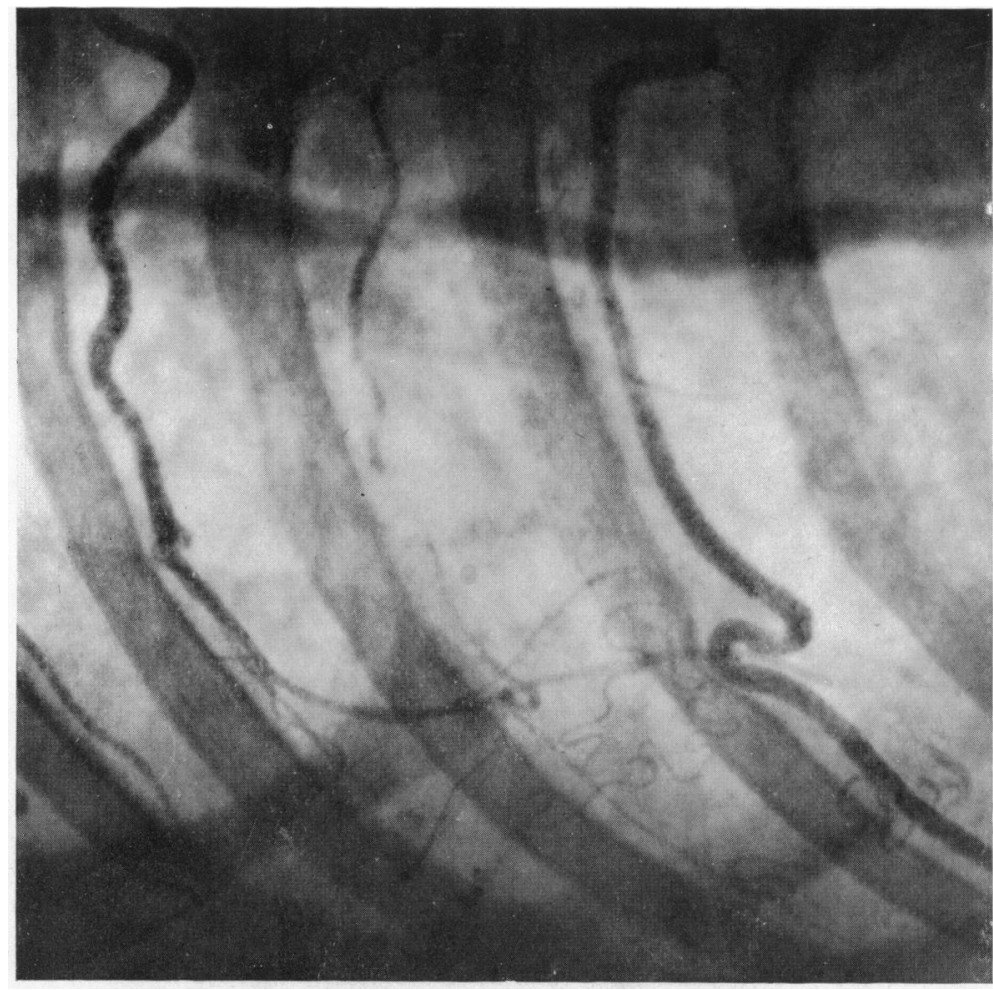

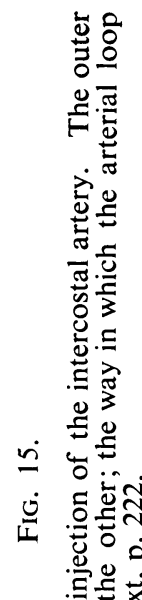

吾艾

กิ

ต유

这管

ษั 잉

达这焉

풀

政

sio.

这的

는

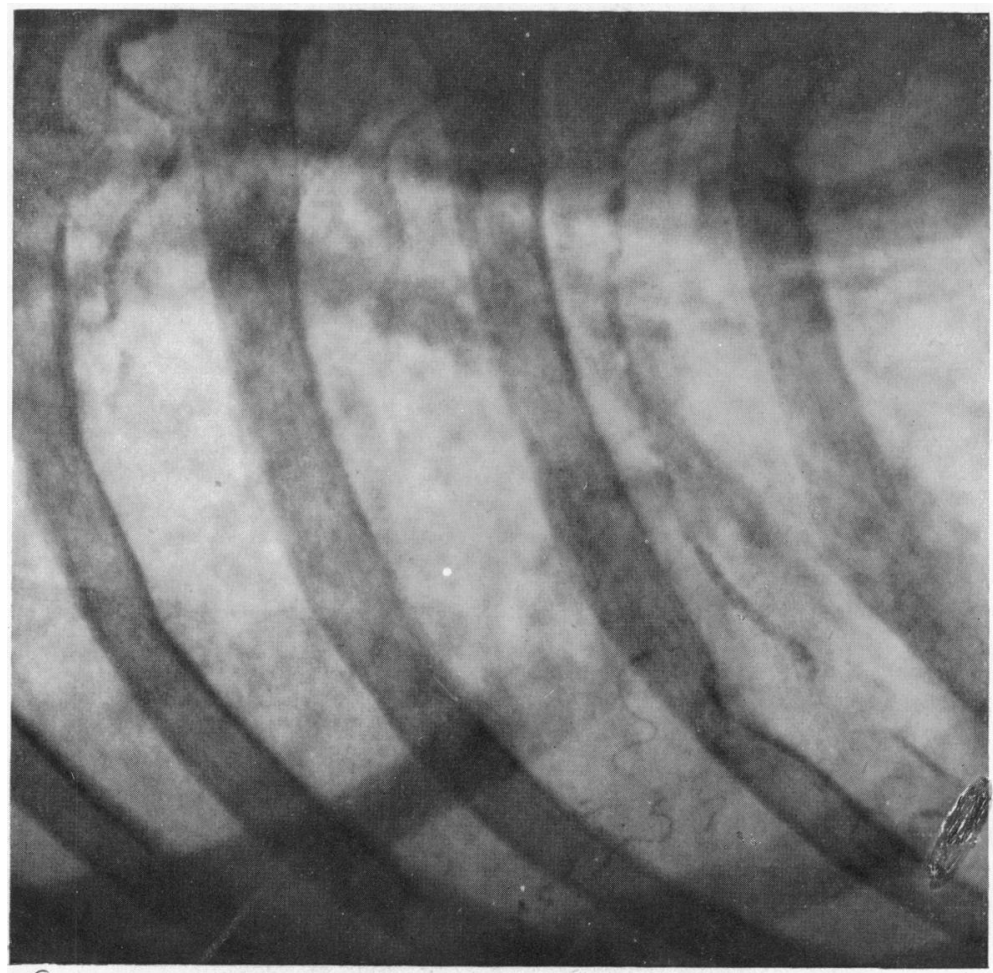


inferior phrenic branches of the abdominal aorta and the smaller superior phrenic branches of the thoracic aorta, forming a network below and above the diaphragm.

(c) By the upper two intercostals, from the superior intercostal, to the upper aortic intercostals.

The importance of the anastomosis between the superior and deep epigastric has been stressed in most accounts, possibly because it is easily palpable. In our case (Fig. 12) it was insignificant. Likewise the anastomosis between the anterior intercostals (arising from the internal mammary) and the terminal branches of the aortic intercostals was poorly developed, the great enlargement of the internal mammary being due chiefly to the extensive diaphragmatic anastomosis. Unfortunately, at the time these observations were made we did not realize the importance of the spinal anastomosis (Table I and Fig. 13), and consequently no attempt was made to study it.

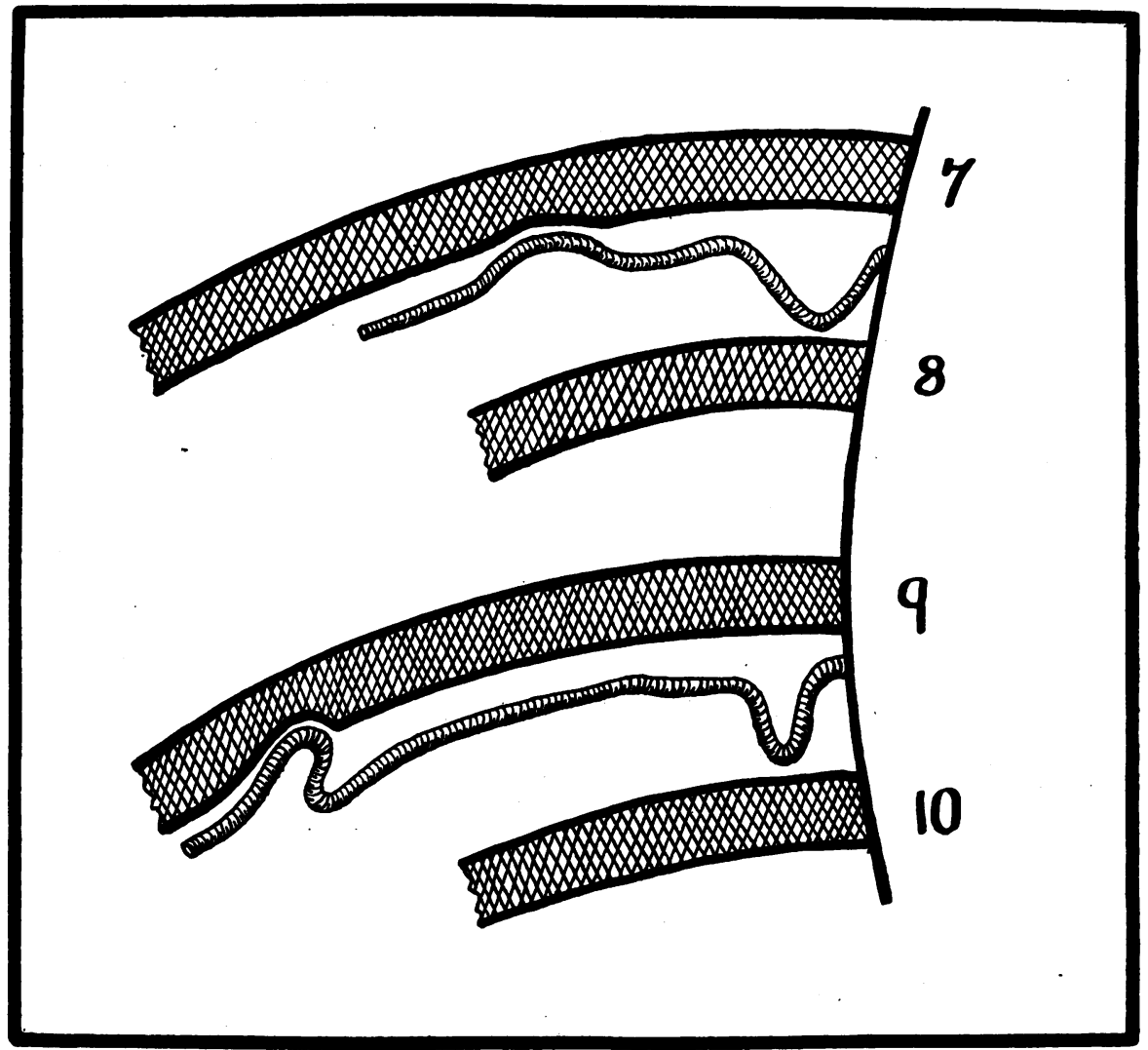

FIG. 16-The formation of rib notches. The two intercostal arteries illustrated are drawn from the seventh and ninth right intercostals shown on Fig. 7. The seventh intercostal forms a smooth, shallow, symmetrical erosion on the seventh rib, but the greater tortuosity of the ninth intercostal produces a notch of characteristic shape. This type of notch can be seen on several ribs in Fig. 7. The drawing also illustrates how the intercostals may be very tortuous near the necks of the ribs without notching them, since here the arteries are some distance from the lower margins of the ribs (see text, p. 222).

$\mathbf{R}$ 


\section{Rib Notching}

(a) The Formation of Notches. It was suggested by Arendt (quoted by Wolke, 1937) that rib notches in coarctation were of two types: shallow notches due to the tortuosity of the arteries, and deeper, punched-out notches due to small aneurysms on the intercostal arteries. Wolke (1937) studied radiographically a single aortic intercostal injected with iodized oil and arrived at the conclusion that it was unnecessary to invoke aneurysm formation, as the tortuosity of the artery was sufficient to account for both types of notch.

Our observations confirm those of Wolke. Fig. 14 and 15 (p. 220) illustrate how an arterial loop may form a notch, and in Fig. 16 we have represented diagrammatically the formation of shallow and deep notches by the different degrees of tortuosity of the intercostal artery. From Fig. 14 and 15 it is clear that the deep notches have a very characteristic shape; they are asymmetrical, with a gradual slope on one side and a steep slope on the other. This shape is determined by the form of the arterial loop, which is remarkably constant; several such loops are visible in Fig. 7.

(b) The Distribution of Notching. The distribution of notching is interesting. The notches in the present case were on the fourth, fifth, sixth, seventh, and ninth ribs on the right and on the fourth, fifth, sixth, eighth, and ninth ribs on the left (Fig. 17). We have studied the distribution of the notching in the radiograms of the other twelve cases in our series. This is tabulated in Table II, (p. 226) illustrated in Fig. 18 (p. 224), and represented graphically in Fig. 19.

The data enumerated indicate that notching is commonly confined to the ribs between the third and the ninth. It is absent in the first two ribs because the upper two intercostal arteries arise from the subclavian by the superior intercostal ; unlike the other intercostals, they arise above the coarctation. Near their origin they give off large branches, which anastomose with the upper aortic intercostals; after this they play no further part in the collateral circulation and do not become tortuous.

The aortic intercostals supply the intercostal spaces from the third downwards. They become tortuous because a large amount of blood enters their dorsal and lateral branches from the scapular network. The number of aortic intercostals that enlarge depends upon the site of termination of the subscapular, posterior scapular, and other descending branches of the scapular network. The shorter collateral channels to the upper aortic intercostals naturally enlarge first, and this is probably the reason why notching seldom extends below the ninth rib.

The notches are always confined to the posterior and lateral portions of the ribs; the anterior portions are never involved. This is probably due to the fact that the main blood flow enters the intercostals by their lateral and dorsal branches, whereas the anterior intercostals, arising from the internal mammary, are comparatively unimportant.

Sometimes, as in the present case, a double series of notches occurs (Fig. 17). When this is so, the inner notches are almost invariably confined to the third, fourth and fifth ribs (Table II and Fig. 18 and 19). The third, fourth, and fifth 
intercostal spaces are the first to be supplied by the aortic intercostals. In the present case the first aortic intercostal supplied the third and fourth spaces; it was greatly enlarged, and its main trunk anastomosed with the superior intercostal (Fig. 11). The second aortic intercostal supplied the fifth space.

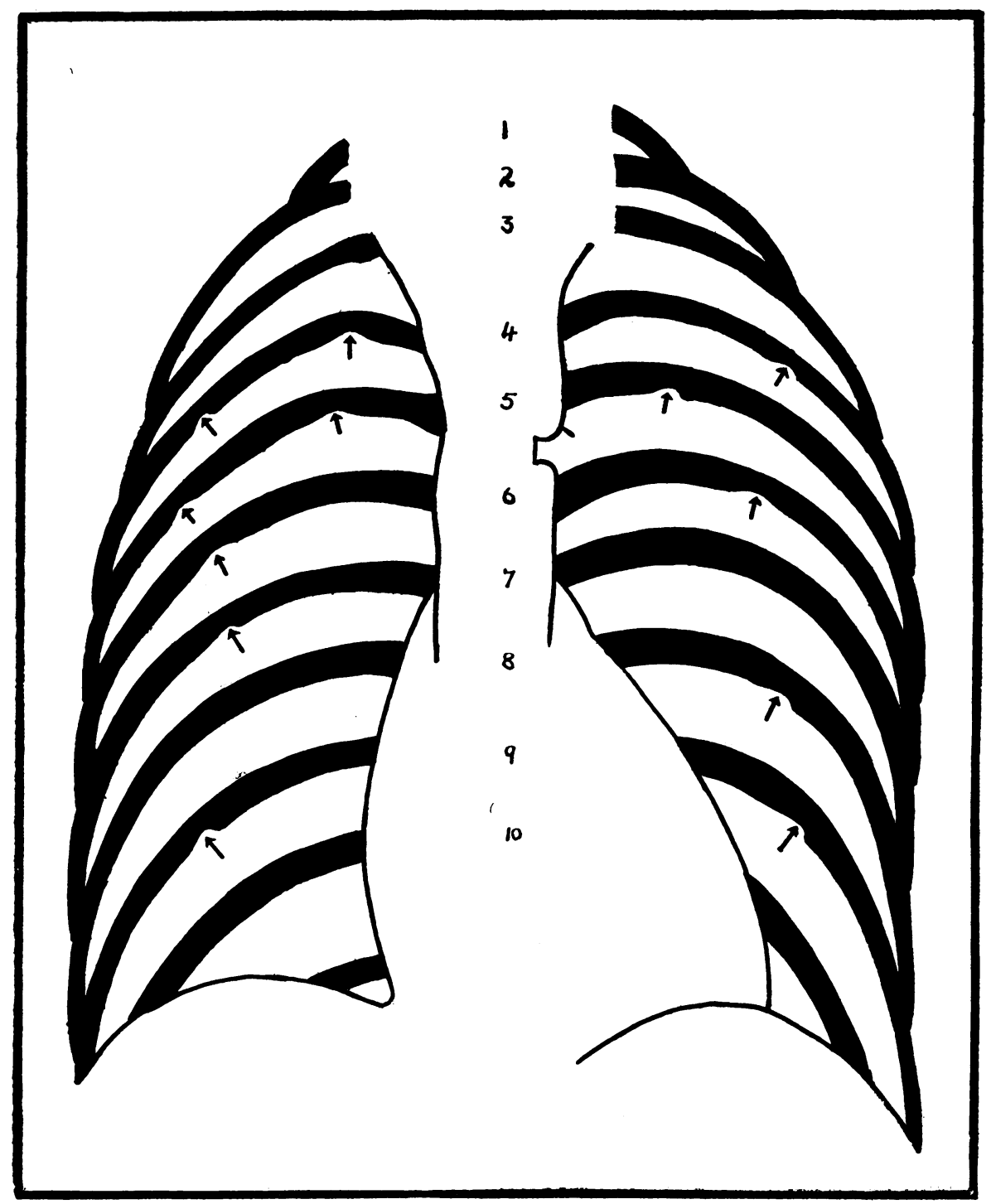

FIG. 17.-The position of rib notches. This diagram is taken from Fig. 6 and illustrates the position of the definite notches in this case.

It was also considerably enlarged, but on both sides it diminished suddenly in size about two inches from the aorta. This occurred because at this point the artery gave off a large branch, which turned upwards towards the superior intercostal. At its origin this branch notched the fifth rib on each side (Fig. 7 and 8); these notches are represented in Fig. 17 and are examples of the 
inner group of notches depicted in Fig. 18. The anastomosis between the upper aortic intercostals and the superior intercostal therefore appears to be responsible for the production of the inner group of notches. This accounts

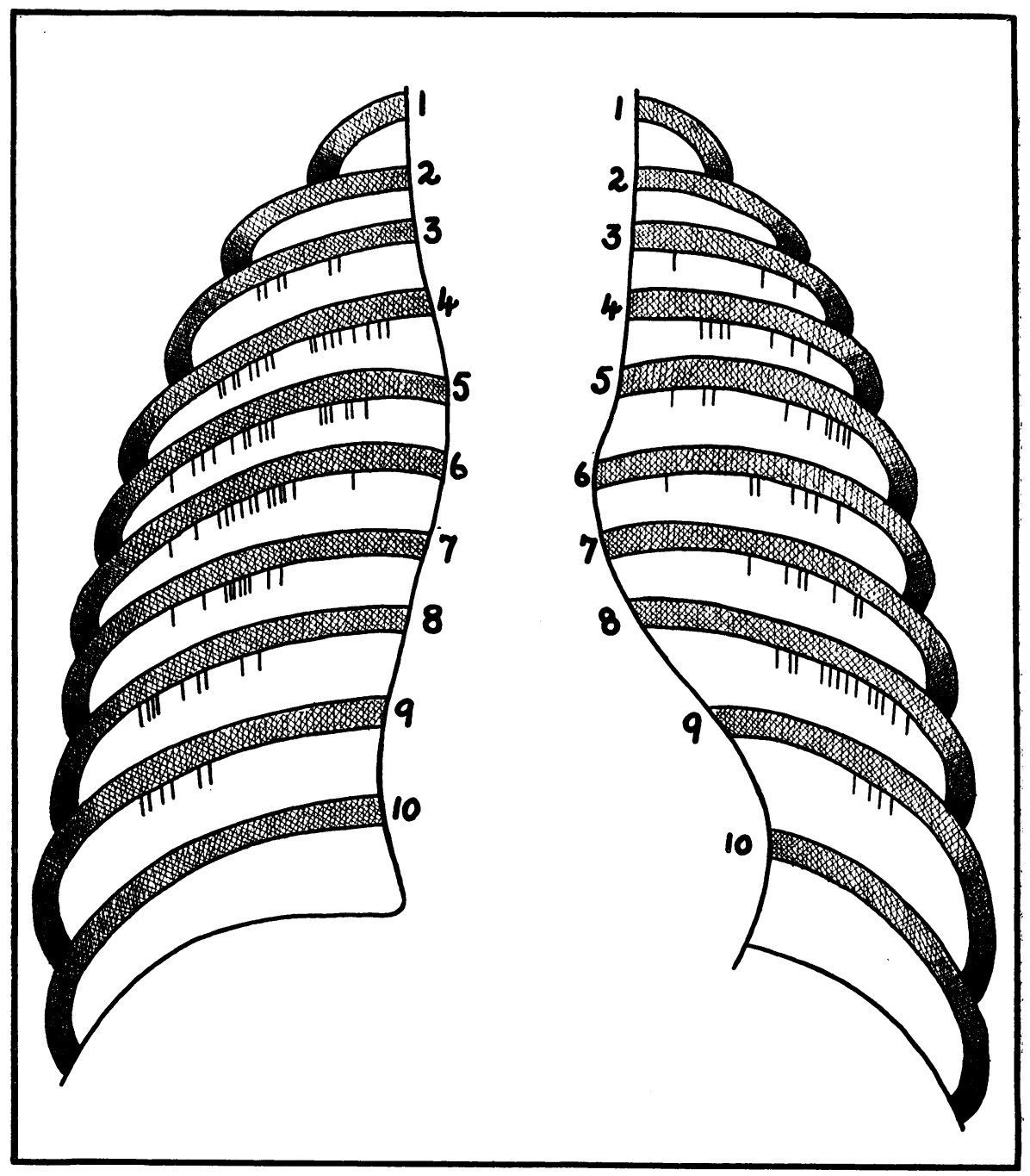

FIG. 18.-The distribution of rib notches in thirteen cases of coarctation of the aorta. The position of the definite notches seen in A.-P. radiograms of thirteen cases have been represented on a single diagram in order to show their positions on each rib and to indicate the ribs most frequently notched. The notches may be separated into an inner group on the third to the sixth ribs and an outer group on the third to the ninth ribs.

for the position of the notches near the spine and for the fact that they occur only on the third, fourth, and fifth ribs.

The outer group of notches is due to the anastomosis of the aortic intercostals with the descending branches of the scapular network and has a different distribution. These notches are situated more laterally, they extend as low as the ninth rib, and are most frequent from the fifth to the eighth ribs (Fig. 19). 
The distribution of the notches in the present case is illustrated in Fig. 17 and is typical. It is striking that the outer notches tend to lie vertically under one another (Fig. 17) and in a fairly constant position (Fig. 18). Notching is due to tortuosity of the arteries, and tortuosity is most likely to occur midway between two fixed points on the artery. In searching for such fixed points one naturally thought of the nutrient branches of the ribs, but these are inconstant in position. The origins of the dorsal and lateral branches of the intercostals,

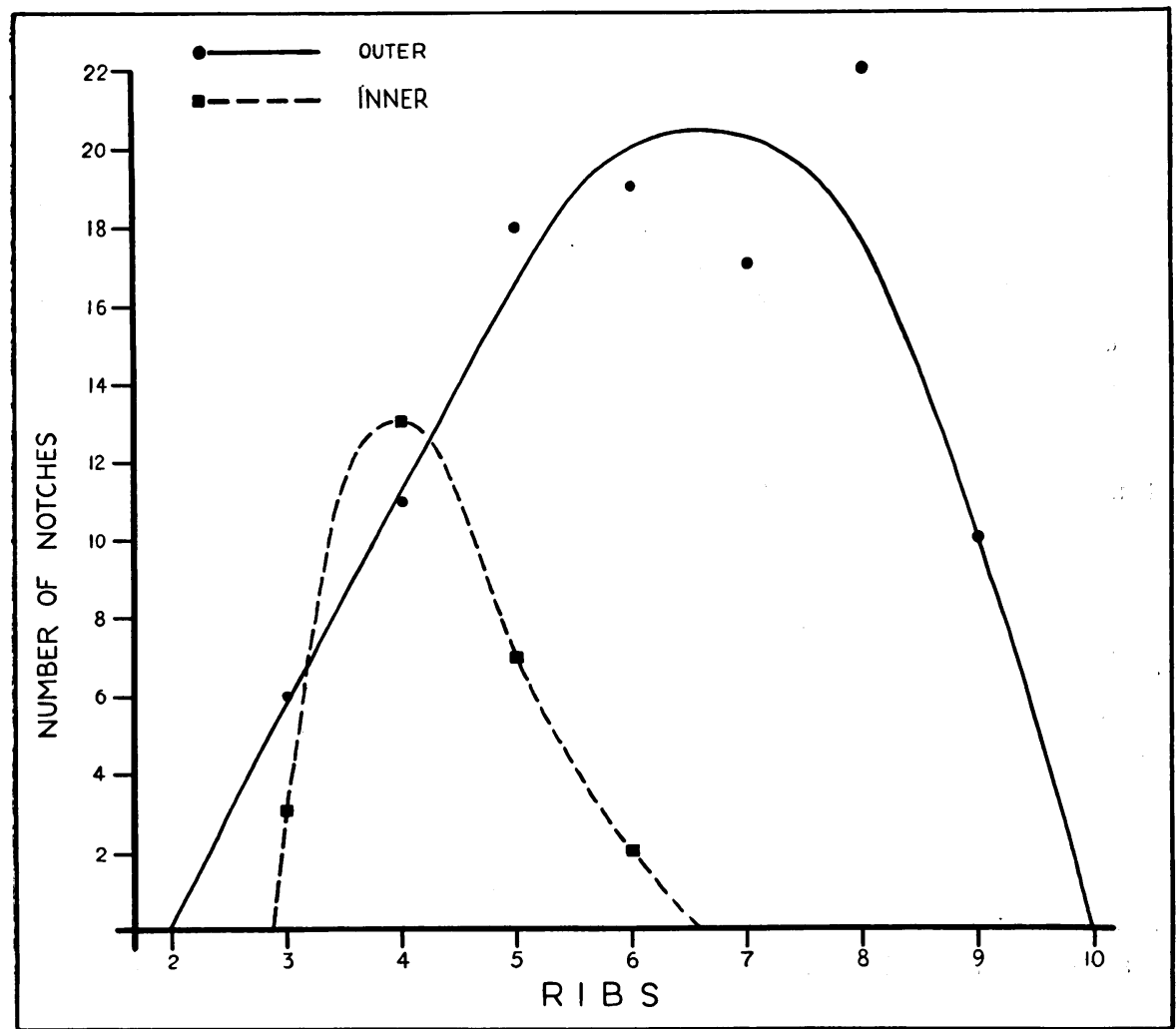

FIG. 19.-Graph illustrating the distribution of rib notching in coarctation of the aorta. The distribution of rib notching illustrated in Fig. 18 has been represented graphically. The curves illustrate how the outer notches occur most frequently on the fifth, sixth, seventh, and eighth ribs, whereas the inner notches are commonest on the fourth rib.

on the other hand, are fairly constant in position, and, because these branches pierce the fascial and muscular planes of the chest wall, they anchor the intercostal arteries at these points. The position of the outer notches supports the hypothesis that tortuosity first develops midway between these two points . The communications between the seventh intercostal and the loop on the ninth right intercostal and between the eighth left intercostal and the loop on the corresponding ninth intercostal (Fig. 7, 8, and 15) are interesting, for they may account for the position of some arterial loops.

Another fixed point is the origin of the intercostal from the aorta. Between this point and the origin of the dorsal branch considerable tortuosity may 
develop (Fig. 7 and 8). This was illustrated diagrammatically in Fig. 16. It is, however, uncommon for notching to occur in this situation, for here the intercostal arteries are not in such close relation to the ribs.

TABLE II

Distribution of Rib Notching in Thirteen Cases of Coarctation of the Aorta

\begin{tabular}{|c|c|c|c|c|c|c|c|c|c|}
\hline \multirow{2}{*}{ Rib } & \multicolumn{3}{|c|}{ Right } & \multicolumn{3}{|c|}{ Left } & \multirow{2}{*}{$\begin{array}{l}\text { Total } \\
\text { Outer }\end{array}$} & \multirow{2}{*}{$\begin{array}{l}\text { Total } \\
\text { Inner }\end{array}$} & \multirow{2}{*}{$\begin{array}{l}\text { Com- } \\
\text { plete } \\
\text { Total }\end{array}$} \\
\hline & Outer & Inner & Total & Outer & Inner & Total & & & \\
\hline 1 & - & - & - & - & - & - & - & - & - \\
\hline $\begin{array}{l}2 \\
3\end{array}$ & $\overline{4}$ & $\overline{2}$ & $\overline{6}$ & $\overline{2}$ & $\overline{1}$ & $\overline{3}$ & $\overline{6}$ & $\overline{3}$ & $\overline{9}$ \\
\hline 4 & 8 & $\overline{9}$ & 17 & 3 & 4 & 7 & 11 & 13 & 24 \\
\hline 5 & 10 & 6 & 16 & 8 & 3 & 11 & 18 & 9 & 27 \\
\hline 6 & 13 & 1 & 14 & 6 & 1 & 7 & 19 & 2 & 21 \\
\hline 7 & 10 & - & 10 & 7 & - & 7 & 17 & - & 17 \\
\hline 8 & 9 & - & 9 & 13 & - & 13 & 22 & - & 22 \\
\hline 9 & 6 & - & 6 & 4 & - & 4 & 10 & - & 10 \\
\hline 10 & - & - & - & - & - & - & - & - & - \\
\hline 11 & - & - & - & - & - & - & - & - & - \\
\hline 12 & - & - & - & - & - & - & - & - & - \\
\hline Totals & 60 & 18 & 78 & 43 & 9 & 52 & 103 & 27 & 130 \\
\hline
\end{tabular}

Rib notching may occur quite early in life. It was well developed in our youngest patient, a boy of 11, and Brown (1939) states that it has been reported at the age of 6 .

Laubry (1937) has reported notching of the ribs in conditions other than coarctation of the aorta. He described six cases of aortic incompetence and of hypertension in which notches were seen. These differed from the notches in coarctation, for they occurred as a rule in elderly subjects, they were shallow, and limited to a few of the lower ribs, and were usually near the spine. They must be extremely uncommon, and their existence does little to diminish the diagnostic value of the discovery of rib notching in coarctation of the aorta.

\section{Pain}

Our patient's principal complaint was pain on exertion, in the scapular region; and pain was the presenting symptom in three other cases in our series. In one of these the patient had first noticed pain in the lower interscapular region at the age of 17 . This persisted, and, at the age of 21 , led him to consult an osteopath, who treated him unsuccessfully for eighteen months by manipulation of the spine. In the other two cases the pain was in the right arm and around the left costal margin respectively.

In two of the four cases reported by King (1926) pain was a prominent symptom. One of his patients, a man of 35 , complained of pain on exertion in the left side of the chest; a year later a similar pain developed in the right chest. In King's other patient, a man of 58, the pain was in the left supraclavicular fossa and left shoulder, and corresponded in position to an area of arterial pulsation. It occurred only on exertion and for a considerable period it was the only symptom. 
These cases illustrate that pain may occur in several situations, but it is always confined to the upper part of the body. It is in this area that the collateral circulation is developed, and in one of King's cases the pain was localized to an area of arterial pulsation.

Enlarged collateral channels might produce pain in several ways. When the pain is in the back it is possible that it may be due to erosion of the ribs, but the frequency with which rib notching occurs without pain throws doubt on this explanation. Pain in the arm, or around the costal margin, is more suggestive of root or nerve pressure, which might be due to the enlarged anastomotic artery passing through the intervertebral foramen (Fig. 13). The relation of the pain to exertion could be explained by the increased blood flow through the tortuous and pulsating collateral channels, and the differing sites of pain may be related to differences in the anastomotic pattern.

These various considerations suggest that the enlarged pulsating vessels of the collateral circulation are instrumental in the production of this symptom, and that in some instances the pain may be due to nerve pressure or to the erosion of bone.

\section{SUMMARY}

1. The post-mortem findings in a patient with coarctation of the aorta who died from subarachnoid hæmorrhage due to a ruptured cerebral aneurysm have been described.

2. As the coarctation had been diagnosed and the condition fully investigated two years previously, it was possible to compare the clinical and postmortem findings.

3. Prior to autopsy the cadaver was injected with barium paste and the arterial anastomoses studied radiographically.

4. The anatomy of the collateral circulation has been described. The factors that determine the distribution of rib notching and some possible causes of pain in this condition have been discussed.

We are grateful to Sir John Stopford for his help and interest in this work; to Mr. F. S. A. Doran, who kindly drew for us Fig. 13; to our colleague, Dr. E. Duff Gray, for the facilities afforded to us in his department, and to Dr. S. Nowell for his valuable help in the radiography of the cadaver.

\section{REFERENCES}

Brown, J. W. (1939). Congenital Heart Disease. London, pp. 56 and 61. Ernstone, A. C. and Robins, J. A. (1931). Amer. J. Roentgen, 25, 243.

King, J. T. (1926). Arch. intern. Med., 38, 69.

Laubry, C. and Balsac, R. H. de (1937). Arch. Mal. Caur, 30, 394

Wolke, K. (1937). Acta Radiol., 18, 319. 